\title{
PLASMA $\beta$ - ENDORPHIN CONCENTRATION AND \\ SCHIZOPHRENIA ACUTE TREATMENT OUTCOME
}

\section{Małgorzata Urban-Kowalczyk ${ }^{1}$, Magdalena Kotlicka -Antczak ${ }^{1}$, Dominik Strzelecki ${ }^{1}$, Ewa Rudecka ${ }^{2,3}$, Janusz Śmigielski ${ }^{4}$}

\section{In minent \\ UNIVERSITY \\ OF LODZ}

\section{OBJECTIVES \\ Some studies indicated the presence of possible excess of opioid in schizophrenia and its relationship with negative symptoms. Neurons containing endorphins modulate dopaminergic neuronal activity which suggests that pathogenesis of schizophrenia may be associated with an imbalance in the modulatory effect of opioids on the dopaminergic system. The specific role of endogenous opioids in ethiopathology of schizophrenia is still unclear}

\section{BACKGROUND AND AIMS}

The study assessed the relationship of $\mathrm{BE}$ concentration and schizophrenia treatment outcome.

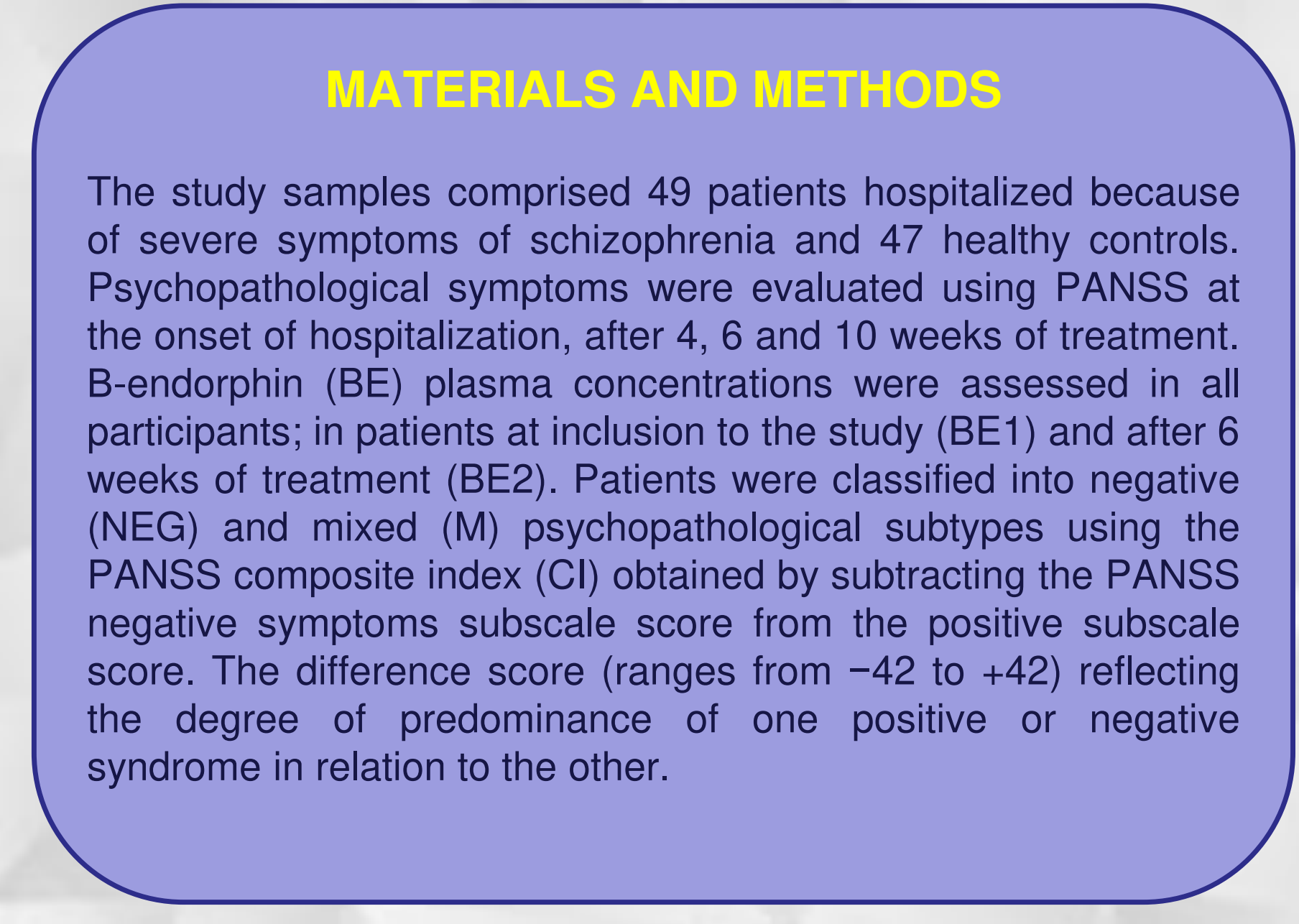

RESULTS

BE concentration among all participants with schizophrenia was significantly higher than in controls at inclusion to the study $(p=0.008)$ and increased after 6 -week treatment (BE1mean $0.52 \mathrm{ng} / \mathrm{ml}$ vs BE2 mean $0.59 \mathrm{ng} / \mathrm{ml} ; \mathrm{p}=0.002)$. Patients with NEG subtype achieved higher reduction in general psychopathology scale than $M$ subtype $(69.5 \%$ vs $32.44 \%)$. BE tended to be higher in patients with lower percent amelioration in negative symptoms. Composite index increased significantly during treatment in NEG group (mean -11.36 vs mean -8.73; $p=0.000$ ) however, after 10 weeks of hospitalization patients achieved similar value like at onset of treatment (mean $=-11.36$ vs mean $=-12.36 ; p=0.268$ ) despite general reduction of psychopathological symptoms severity. Higher BE2 concentration correlated with predominance of negative symptoms after 10 weeks treatment in both patients samples (NEG: $r=-0.557, p=0.071 ; \mathrm{M}: r=-0.585, p=0.0013$ ).

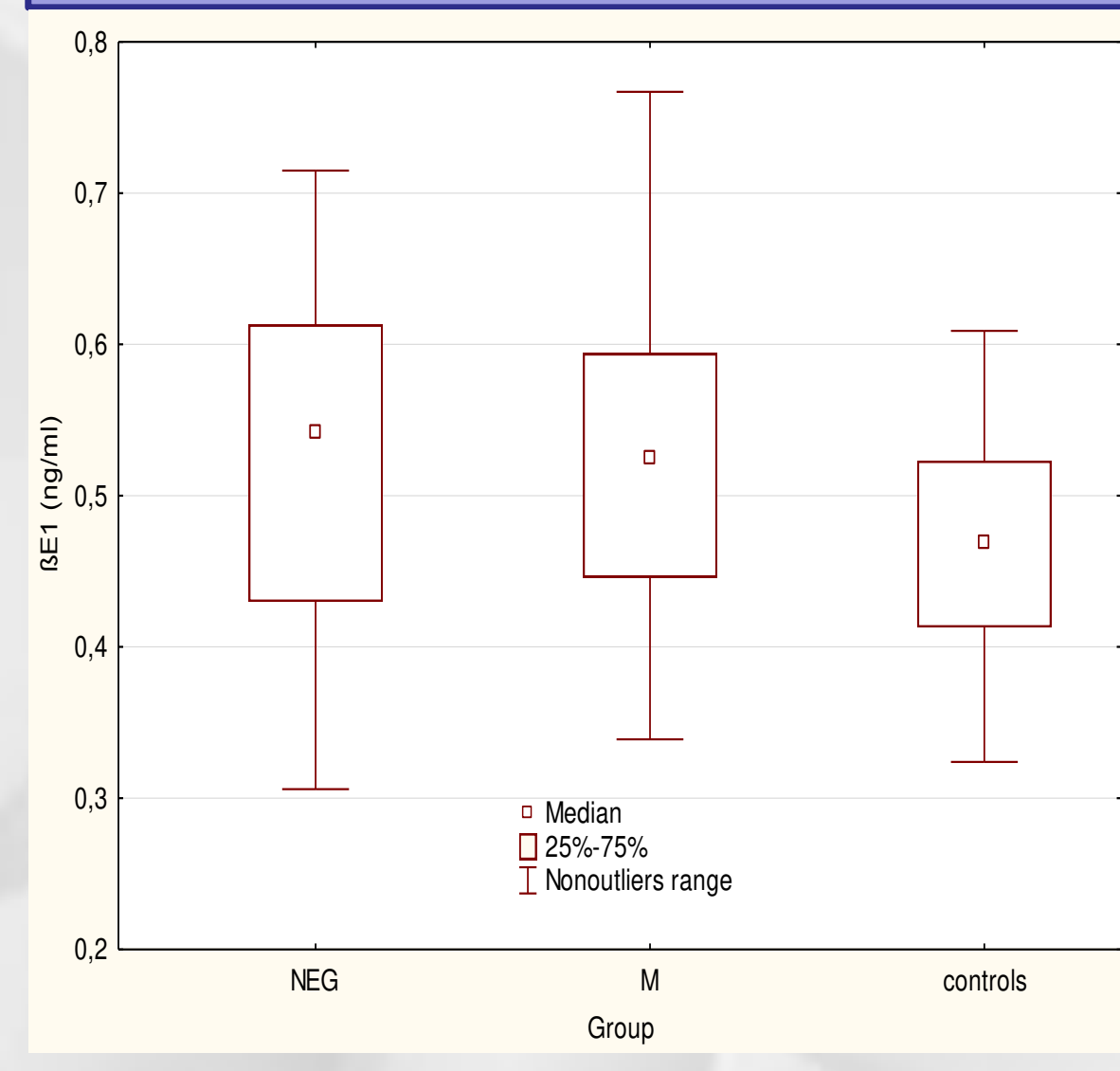

Figure 1. Blood concentration of BE1 in study groups

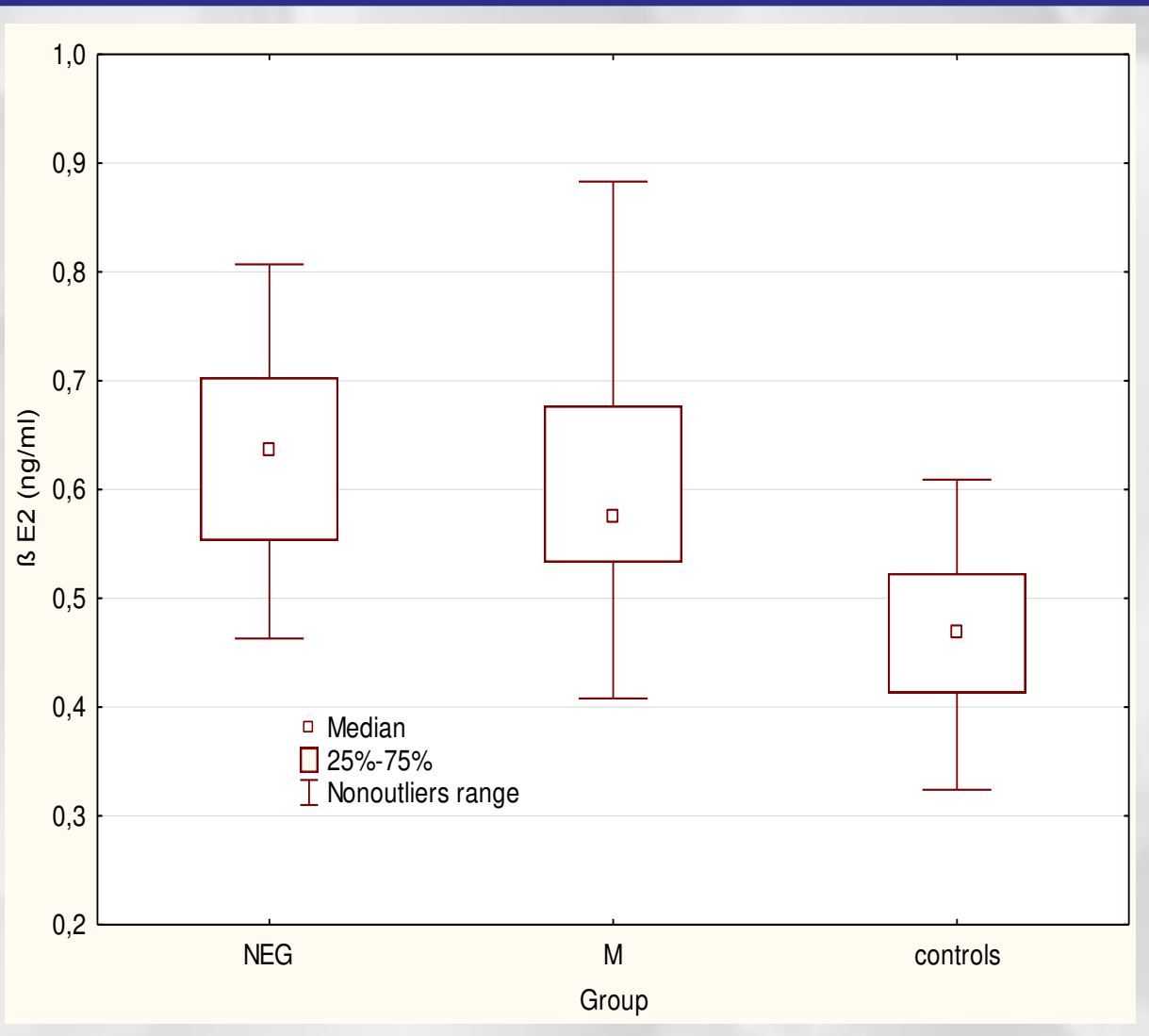

Figure 2. Blood concentration of BE1 in study groups

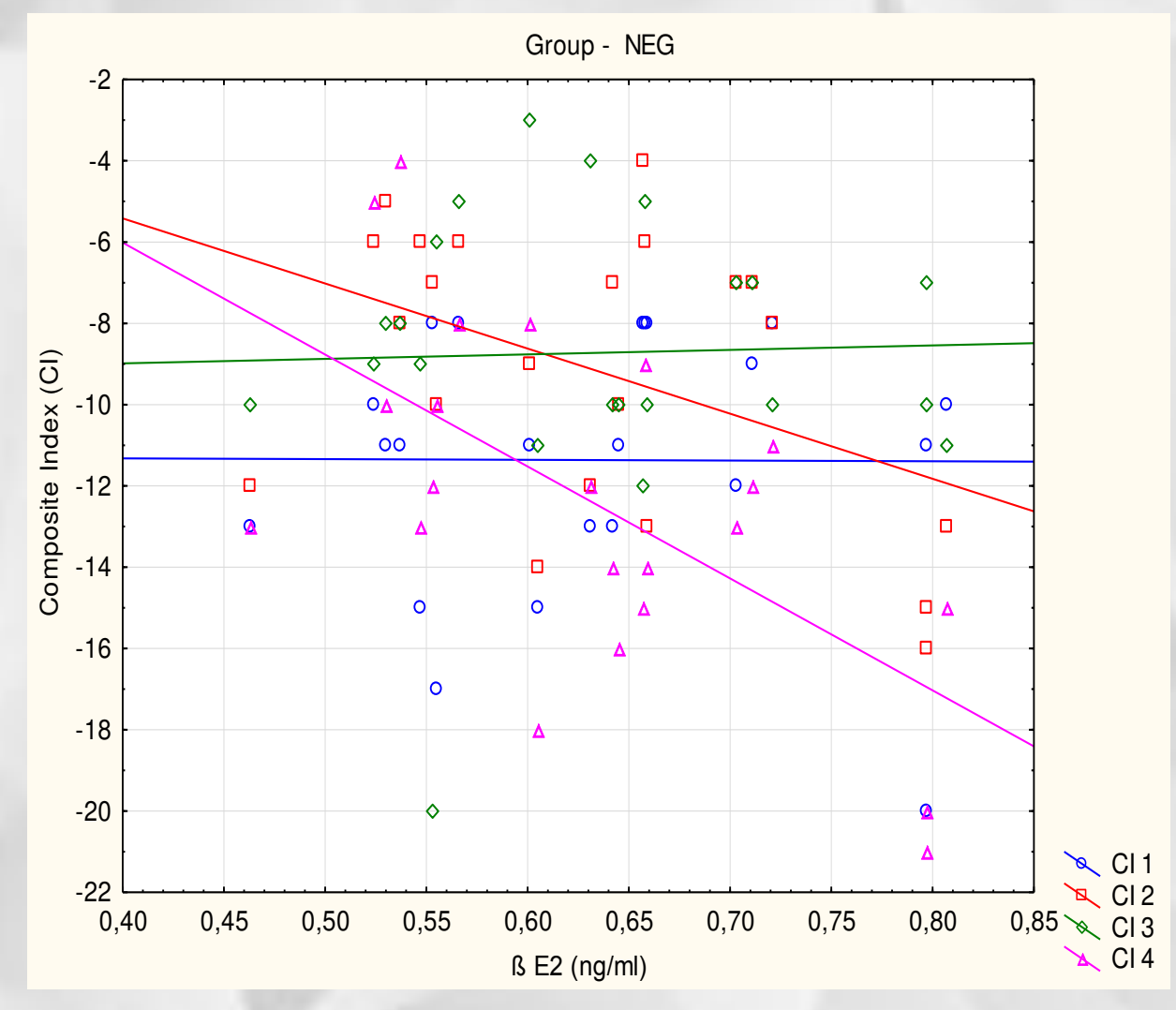

Figure 3. The relationship between Composite Index value and BE2 blood concentration in NEG group

\section{CONCLUSIONS}

$\mathrm{BE}$ is involved in ethiopathology of schizophrenia. It might determine specific pattern of psychopathological manifestation and might be related with persistence of negative symptoms of schizophrenia even after effective pharmacological treatment. 